International Journal of Applied Linguistics \& English Literature

ISSN 2200-3592 (Print), ISSN 2200-3452 (Online)

Vol. 1 No. 7; November 2012 [Special Issue on Applied Linguistics]

\title{
Politeness Accommodation in E-Mail Requests among Iranian Postgraduate Students of EFL
}

\author{
Muhammed Parviz (Corresponding author) \\ English language Department, Foreign Language Center \\ Imam Ali University \\ Hor Square, Imam Ali University, Tehran, Iran \\ Tel: +989351381105, E-mail: Mohammad. Parviz@aol.com
}

Received: 25-09- 2012

Accepted: 27-10- 2012

Published: 25-11- 2012

doi:10.7575/ijalel.v.1n.7p.127

URL: http://dx.doi.org/10.7575/ijalel.v.1n.7p.127

\begin{abstract}
Computer-mediated communication (CMC) offers us a chance to understand how social relationships are built and maintained in an environment in which interlocutors not only lack the paralinguistic features that are vital to face-to- face conversation, but are participating in a medium which has had little time to develop rules of conduct. The present study was an attempt to determine politeness accommodation in e-mail messages among Iranian postgraduate students of EFL. One hundred EFL learners, aged 22-26, participated in this study. Four different message types were constructed and sent to the participants, i.e. messages with verbal politeness markers; messages with structural politeness elements (e. g., salutation and closing remarks); messages with both verbal and structural politeness indicators; finally messages with neither verbal nor structural politeness indicators. Further, the messages varied in their degree of politeness; however, their content was the same. Results showed that the participants accommodated significantly to verbal politeness indicators in the body of a message, and to structural politeness indicators of greeting/salutation. When such indicators were included in messages, the participants responded with significantly more polite messages (greeting and body) than when the indicators were absent. The results boost our understanding of CMC with reference to politeness markers, and how they are used by Iranian EFL learners.
\end{abstract}

Keywords: Computer-mediated communication, Politeness, Negative politeness, Positive politeness, Face

\section{Introduction}

Politeness has become one of the fields of research to which more attention has been devoted in the last two decades. The connection of politeness studies with other domains, such as sociolinguistics and socio-pragmatics, ethnography of communication, second language teaching/acquisitions or conversation analysis, have definitely contributed to this growing interest. According to House (2005), politeness is a basic socio-psychological guideline for human behavior, thereby informing an integral part of all human interaction.

Politeness can be defined as the means employed to show awareness of another person's face. Haugh (2004) suggests that politeness involves speakers' showing what they think of themselves and others, and addressees' perceptions of those evaluations. More specifically, it arises when an addressee thinks a speaker is showing that he or she thinks well of the addressee or not too highly of himself or herself. According to Yang (2007, p. 155), "the degree of indirectness and politeness indicates the speaker's view of the degree of formality of a situation, the relationship between him and the hearer, his judgment of the imposition on the hearer, and so on". According to Brown and Levinson (1987), and Leech (1983), direct requests appear to be inherently impolite and facethreatening because they intrude in the addressee's territory, and these authors argue that the preference for polite behavior is indirectness. Leech (1983, pp. 131-32) suggests that "it is possible to increase the degree of politeness by using more indirect illocutions". Generally, most of the problems that EFL learners face in e-mail communication may stem from their lack of knowledge about politeness in relation to e-mails. Research has shown that L2 learners regularly perform speech acts such as requests, apologies, and refusals in accordance with the sociolinguistic norms of their L1. As Kasper (1992 ,pp. 211-212) argues:

Adult learners have fully developed sociolinguistic knowledge in their native 
International Journal of Applied Linguistics \& English Literature

ISSN 2200-3592 (Print), ISSN 2200-3452 (Online)

Vol. 1 No. 7; November 2012 [Special Issue on Applied Linguistics]

language and therefore they have been shown to display sensitivity towards

context-external factors such interlocutors' familiarity and relative status and

context-internal factors such as degree of imposition, legitimacy of the requestive

goal and standardness of the situation in requesting and severity of offence,

obligation to apologize, and likelihood of apology acceptance in apologizing.

This means that both native and non-native speakers vary their strategies in different contexts, although L2 learners' variation might follow their own L1 sociolinguistic patterns. Furthermore, as politeness accommodation is an important need for university students in their attempts to be communicatively effective, this study, therefore, focused on politeness accommodation in e-mail messages in an EFL environment. It was an attempt to find the extent to which politeness was mirrored in e-mail messages of Iranian postgraduate EFL learners. The present study was inspired by Buzzanell, Burrell, Stafford and Berkowitz (1996) study on politeness accommodation in telephone messages. These researchers explored whether callers converge to structural (script and message features) and relational (verbal immediacy cues) message aspects found in recorded answering machine messages. From their point of view, structural messages can be defined as greetings, terms of address, signs of appreciation, and closings. They also argued that through verbal immediacy people are drawn toward persons and things that they like, evaluate highly, and prefer. Such preferences are reflected in, or marked by, verbal and nonverbal behaviors people exhibit. Immediacy messages indicate that interactants like and respect each other, whereas nonimmediacy is associated with impressions that one's interaction partner is unemotional, distant, higher in status, and detached from the interpersonal encounter. Immediacy messages enhance outcomes, such as positive attitudes toward work, good teacher-student relations, and increased student learning. Furthermore, through the use of verbal immediacy cues, people signal interest in, desire to, and preference for interacting with other people. The present study was an attempt to investigate politeness accommodation in e-mail messages by Iranian EFL learners. Social context cues are often assumed to indicate politeness in CMC messages. It is possible that individuals may converge to these cues when interacting with others via e-mail. Despite the extensive literature investigating the use of politeness in various languages and cultures, studies addressing politeness accommodation in relation to e-mail messages of Iranian EFL learners are very limited and this area needs more treatment. Accordingly, the following research questions were investigated in this study:

1. To what extent do Iranian EFL learners converge or diverge in terms of accommodating to politeness in e-mail messages?

2. To what extent do EFL learners accommodate to politeness in e-mail messages through converging to verbal markers?

3. To what extent do EFL learners accommodate to politeness in e-mail messages through converging to structural elements?

4. To what extent do EFL learners accommodate to politeness in e-mail messages through converging to both verbal and structural politeness markers?

\section{Background to the Study}

\subsection{Computer-mediated communication (CMC) and Politeness}

In the last few decades, a rapid diffusion of electronic media has led to a significant field of study: computer-mediated communication $(\mathrm{CMC})$. CMC "refers to person-to-person communication... over computer networks" (Pickering \& King, 1995, p. 479), and is generally understood to include technologies such as e-mail, computer conferencing, online discussion boards, Multi-User Domain (MUDs) and Multi-User Object Oriented environments (MOOs), and more recently online instant messaging and even short message sending via cell phones. Today, CMC is being used as a convenient measure to construct a new type of social interaction beyond space barriers.

$\mathrm{CMC}$ is a widely used means of communication and has proven to influence the way people use language in interpersonal, organizational, and pedagogical settings. Studies have suggested that social and professional standing seems to become equalized, meaning politeness and correctness in communication across the status lines. In fact, there is evidence that CMC can result in the use of flagrant and hostile language, or 'flaming' (Kiesler, Siegel \& McGuire 1984; O’Sullivan \& Flanagin 2003; Siegle, Sproull, \& Kiesler 1986). In comparing CMC and face-to-face communication, Sproull and Kiesler (1986) observed that CMC communication resulted in messages that not only were uninhibited across status lines but were also self-absorbed. The authors believe that 
International Journal of Applied Linguistics \& English Literature

ISSN 2200-3592 (Print), ISSN 2200-3452 (Online)

Vol. 1 No. 7; November 2012 [Special Issue on Applied Linguistics]

the absence of social context cues in CMC communication, as opposed to face to face communication, led to the equalized language in the messages. Countering these findings, however, is research showing that online interaction between people can positively influence relationships and contribute to more personal interaction.

CMC provides a link between oral and written communication, producing a "categorical change, which affects not only the notion of what the conversation is but the speaking-writing dichotomy as well" (Noblia, 1998, p. 10 ). Use of CMC is not restricted to formal, organizational e-mails but is also widely used for informal communication. A big part of the work on the psychological and sociological impacts of $\mathrm{CMC}$ assumes that the computer itself in a text-based medium has the sole influence on communication outcomes. Since this approach assumes the elimination of physical and social cues, sometimes it is called "cues filtered out" approach (Culnan \& Markus 1987; Walther, 1992). Because computer- mediated interactants in a text-based medium cannot see, hear, feel each other, the absence of regulating feedback (e.g., gestures, nods, the tone of voice) may cause coordination problems and deprive interactants of salient social cues. In the absence of the social context cues and of the nonverbal behavior, computer-mediated communicative discourse is left in a social vacuum quite different from face-to-face interaction; this is often quite important in bargaining situation (Kiesler, Siegel, \& McGuire 1984).

Thus, cues-filtered-out theories characterize CMC as less personal, lacking social presence, and enabling very little socioemotional and relational communication. The cue-filtered-out model is based on the concepts of bandwidth and social presence (Dulther, 2006). Walther and Parks (2002, cited in Duthler, 2006) define bandwidth as "... the number of communication cue systems a technology can convey, specifically, the incremental addition to verbiage of voice, kinesics, and proxemics". In contrast to the cues-filtered-out model, the hyper-personal model (Walther, 1996, p. 13) suggests that CMC can facilitate more socially desirable levels of interaction than face-to-face communication precisely because of its lower bandwidth. Partial cues in CMC allow users to employ visual anonymity strategically. Common identity cues such as gender or physical ability are not immediately apparent. CMC users can manipulate these cues to optimize their self-presentation. In combination with this identity optimizing effect, receivers formulate idealized perceptions of the sender. Cues such as language use or timing of self-disclosure are among the few mechanisms by which one can form an opinion of the other's identity. As the sender successfully manipulates these cues, the receiver creates an idealized perception of his or her conversational partner.

Asynchronicity, a property of many forms of CMC, further encourages selective message construction. During asynchronous interactions, individuals are better able to plan, compose, edit, and review message content, as well as to time self-disclosure and message exchange with more forethought. In asynchronous CMC, one can divide the cognitive load of message construction across more moments than in instantaneous, simultaneous face-to-face interaction. "Asynchronous interaction may thus have the capacity to be more socially desirable and effective as composers are able to concentrate on message construction to satisfy multiple or single concerns at their own pace" (Walther, 1996, p. 26).

\subsection{Communication Accommodation Theory (CAT)}

Communication accommodation theory (CAT) is based on the premise that speakers and listeners unconsciously and mutually modify their linguistic (e.g., language choice and vocabulary) and/or paralinguistic (e.g., dialect, tone of voice and speech rate) behaviors to become more similar to (convergence) or different from (divergence) their interactional partners (Giles, Mulac, Bradac \& Johnson, 1987). Convergence strategies signal interactants' positive attitude toward each other, such as increasing attractiveness and approval or showing solidarity, whereas divergence strategies accentuate differences between interactants (Giles et al., 1987). Besides convergence and divergence, interactants may continue using their own styles (maintenance) without reference to partners' cues or, perhaps, as a deliberate reaction to partners' strategies (Bourhis 1979, cited in Bunz \& Campbell, 2002). CAT addresses behavioral adjustments individuals make during communication in order to express values, attitudes, and intentions (Bunz \& Campbell, 2002). Specifically, CAT sets out "to clarify the motivations underlying, as well as the constraints operating upon, speech shifts during social interactions and the social consequences of these" (Giles, et al., 1987, p. 14). When Giles (1973, cited in Bunz \& Campbell, 2002) first introduced accommodation theory, he illustrated convergence by reporting that individuals in the interview situations adjusted their accents toward that of the interviewer.

\subsection{Theoretical Perspectives on Politeness}

When people are involved in conversation, they individually consider certain variables, whether consciously or subconsciously, that help them determine the form that their speech will take. Goffman (1995) called these variables "face," and defined it as "the positive social value a person effectively claims for himself by the line others 
International Journal of Applied Linguistics \& English Literature

ISSN 2200-3592 (Print), ISSN 2200-3452 (Online)

Vol. 1 No. 7; November 2012 [Special Issue on Applied Linguistics]

assume he has taken during a particular contact" (Goffman, 1955, p. 213). Brown and Levinson (1978) using Goffman's definition of "face" as a starting point, proposed a comprehensive and, according to Brown and Levinson, universal theory of politeness. Brown and Levinson (1987) claim that there are two dimensions underlying politeness phenomena across all cultures. The first dimension is positive face, which is defined as " the desire that one's wants be desirable to at least some others, while the second dimension is defined as the desire that one's actions be unimpeded by others, or what they call negative face" (Brown \& Levinson 1987, p. 62). Positive politeness means that "the speaker attempts to save the hearer's positive face by reducing the distance between them. By negative politeness, on the other hand, the speaker attempts to keep the hearer's negative face by valuing the hearer's personal territory" (Brown \& Levinson, 1987, pp. 68-71). Brown and Levinson (1989) maintain that negative politeness strategies are usually used whenever the hearer is assumed to have high power over the speaker or the distance between the two is high. In positive, however, the hearer is assumed to have no (or low) power over the speaker. It is meant, then, to be more informal. Tracy (1990, p. 210) agrees that "positives face concerns the desire to be appreciated and approved of by selected others. Negative face concerns a person's want to be unimpeded and free from imposition". Another assumption Brown and Levinson make is that the speaker is "endowed with... a precisely definable mode of reasoning from ends to the means that will achieve those ends" (Brown \& Levinson, 1987, p. 63). These assumptions are crucial to their theory because they believe that a person will consider the best politeness strategy possible before performing a face-threatening act (FTA). When an act of verbal or nonverbal communication "run[s] contrary to the face wants of the addressee and/or the speaker (Brown \& Levinson, 1978, p. 70), this is called an FTA. An FTA is any utterance that intrinsically threatens another's face (positive and negative) and includes disagreements, criticism, delivery of bad news, and requests. For example, simple requests threaten the target's negative face because the target's compliance with the request interferes with his or her desire to remain autonomous. Criticism threatens the positive face of the recipient because it threatens his or her desire for approval. Holtgraves and Yang (1992, p. 246) define politeness as "phrasing one's remarks so as to minimize face threat".

Brown and Levinson (1987) propose that when confronted with the need to perform an FTA, the individual must choose between performing the FTA in the most direct and efficient manner, or attempting to mitigate the effect of the FTA on the hearer's positive or negative face. The mitigation strategies are what Brown and Levinson (1987) labeled politeness strategies. For example, suppose a student desires to meet with a professor in order to better understand a concept discussed in class. The request to meet with the professor threatens the professor's negative face by disrupting his/her desire to be left alone and autonomous. In making the request, the student can take one of five courses of action, listed in increasing order of politeness: (1) The student can simply state the request baldly on record in the imperative and most direct and efficient way (e.g., Meet with me!); (2) The student can express solidarity or affinity by phrasing the request using positive politeness (e.g., Let's meet to discuss your ideas); (3) The student may attempt to minimize the imposition by wording the request with restraint or negative politeness ( e.g., Would you be willing to meet with me for just a minute about this concept?); (4) The student can make an off-record request by hinting or using ambiguous language to minimize the threat and provide deniability ( e.g., Usually when I talk through a concept, I can understand it better); (5) Or the student may not make the request at all.

\section{Method}

\subsection{Participants}

One hundred male and female EFL students participated in this study. They were Masters of Arts (M.A.) students studying at both State universities (Allameh Tabatabaee University, Tehran University, Shahid Chamran University of Ahvaz, Tarbiat Modares University, Iran university of Science \& Technology, and Tarbiat Moalem University) and Azad Universities (Science and Research University of Ahvaz \& Science and Research University of Tehran, Boroujerd Islamic Azad University, and Esfahan Islamic Azad University) in Iran. They were postgraduate students of TEFL (61\%), Translation Studies (20\%), English Literature (11\%), and Linguistics (8\%) at Iranian universities (See Table 1). Their age range was 22-26, and they used e-mail 3-4 hours per week. They had been using e-mail for an average of over 7 years. $47 \%$ of the participants reported using e-mail for task-related purposes like school or work. $27 \%$ of them reported using e-mail for social reasons such as interacting with friends and family. All the participants had already studied English as their major for at least 5 years. They had all passed the General English Language Proficiency test by taking the Iranian National M.A. Entrance Exam which is a highly competitive exam; therefore, they were assumed to possess a fairly high command of English. 
International Journal of Applied Linguistics \& English Literature

ISSN 2200-3592 (Print), ISSN 2200-3452 (Online)

Vol. 1 No. 7; November 2012 [Special Issue on Applied Linguistics]

Table 1. Distribution of Participants' Major

\begin{tabular}{lcc}
\hline Major & Frequency & Percent \\
\hline TEFL & 61 & $61 \%$ \\
Translation Studies & 20 & $20 \%$ \\
English Literature & 11 & $11 \%$ \\
Linguistics & 8 & $8 \%$ \\
Total & 100 & $100 \%$ \\
\hline
\end{tabular}

\subsection{Instruments}

Information about the participants' age, gender, e-mail experience, weekly e-mail use, and the purpose of e-mail use were collected through a self-report questionnaire. The other instrument developed was e-mail messages sent to the participants. Because the purpose was to elicit the response of the participants, the content of the e-mails was designed around a request for participation in a project. This is a familiar topic usually exchanged via e-mail and it was assumed to cause little difficulty for participants in imagining the situation. Therefore, four different message types were constructed and sent to the participants randomly: messages with verbal politeness markers (e. g., 'please' and 'thank you'); messages with structural politeness elements (e. g., salutation and closing remarks); messages with both verbal and structural politeness indicators; finally messages with neither verbal nor structural politeness indicators. Although the messages varied in their degree of politeness, their content was the same.

\subsection{Procedure}

This study sought to identify whether EFL learners accommodated to politeness markers when interacting with others via e-mail. Following Brouwer (1982, cited in Tracy, 1990), salutations (like 'Dear' + participants' name), acclamations, and closing remarks (like 'Regards') were taken as politeness cues because they conveyed an increased level of respect and formality. The participants were notified by their instructors that their assistance with regard to filling out a questionnaire for a research project was needed. They were notified that they will be contacted via e-mail with more information if they provided their e-mail address to their instructors. Once the e-mail addresses of the participants were obtained, each participant was sent an e-mail message. Accordingly, one hundred e-mails were sent to the intended participants (See Table 2). The purpose was to evoke e-mail responses to assess the extent to which the participants converged to the researcher's e-mail request with specific politeness markers. The participants were thus required to respond to the message in at least one paragraph in length so that it would be adequate enough to allow the researcher to examine the politeness features in them. All messages were sent by the researcher to equalize status differences and control for preexisting personal relationship. The messages were manipulated in terms of politeness markers although they shared the same content.

\subsection{Data Analysis}

Content analysis of the e-mail responses from the participants was conducted. The researcher, based on the review of the related literature and his identification of the politeness markers, agreed on a coding scheme for identifying politeness elements in the messages. Thereafter, $10 \%$ of the messages were randomly chosen and examined by researcher. After reaching a general consensus on politeness cues, the researcher identified and counted different politeness elements in the responses and tabulated the frequency of use of these elements. The participants' response to messages containing either please or thank you or similar expressions of appreciation like I'd be glad or I would be happy were taken as verbal politeness markers. Messages containing both verbal markers (e.g., Please, or Thank you) and structural markers (e.g., Dear, or Regards) were considered the most polite in terms of structure than messages containing only one of the two elements. The final set of the messages included neither verbal politeness markers nor structural elements, which were labeled as None (See Table 2). The number of e-mails sent to the participants was 100 , thirty four of which were of the structural type, 23 verbal politeness, 21 of both structural and verbal type, and 22 requests without any politeness or structural markers (i.e., None) in them. The types of e-mail responses received were coded, and classified with regard to their content. Those responses in which, based on CAT, no convergence occurred were labeled as non-accommodation responses. No accommodation means that the expected convergence did not take place and the received e-mails did not contain either verbal or structural politeness indicators. In such messages, the participants did not modify their linguistic (e.g., language choice and vocabulary) and/or paralinguistic behaviors to accommodate to the message sent to 
International Journal of Applied Linguistics \& English Literature

ISSN 2200-3592 (Print), ISSN 2200-3452 (Online)

Vol. 1 No. 7; November 2012 [Special Issue on Applied Linguistics]

them. Further, responses in which the participants did not accommodate fully to the messages in terms of verbal and structural markers were taken as partial accommodation cases. For instance, a number of the participants were significantly more polite in the form of greetings of their responses but not in the closing section. E-mail responses that fully converged in terms of their use of relevant politeness markers were taken as instances of full accommodation.

Table 2. Frequency and Percentage of the Sent and Received E-mails

\begin{tabular}{|l|c|l|c|c|}
\hline \multicolumn{1}{|c|}{ E-mail Sent with } & Frequency & E-mails Received with & Frequency & $\begin{array}{c}\text { Percentage } \\
\text { Convergence }\end{array}$ \\
\hline $\begin{array}{l}\text { Structural politeness } \\
\text { Markers }\end{array}$ & 34 & Structural Markers & 33 & 97 \\
\hline Verbal Politeness Markers & 23 & Verbal Politeness Markers & 5 & 22 \\
\hline $\begin{array}{l}\text { Both Structural and Verbal } \\
\text { Politeness Markers }\end{array}$ & 21 & $\begin{array}{l}\text { Both (Structural Politeness } \\
\text { Markers) }\end{array}$ & 19 & 90 \\
\hline None & 22 & None & 11 & 50 \\
\hline Total & 100 & & & \\
\hline
\end{tabular}

\section{Results}

\subsection{Research Question 1}

Overall, the extent of full accommodation (convergence) was found to be $62 \%$ and the extent of nonaccommodation (divergence) was found to be $38 \%$. To delve more into the nonaccommodation replies, the researcher analyzed them with regard to their content and classified them into two groups. The first group was labeled as partial accommodation, and the second as unexpected accommodation. The extent of partial accommodation was found to be $9 \%$, and that of unexpected accommodation was found to be $8 \%$.

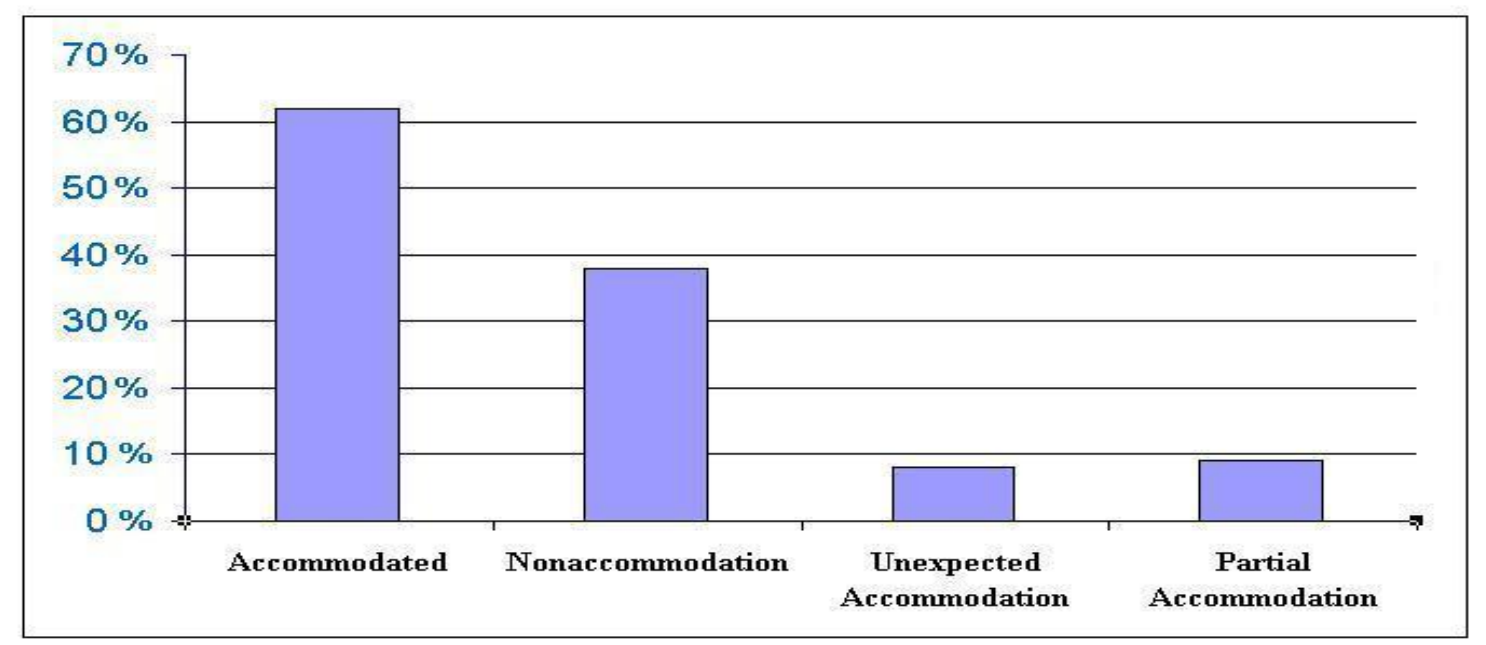

Figure 1. Distribution of the Received E-mails in terms of the Participants' Accommodation Degree

A small group of participants performed the unexpected act of politeness, i.e. they went beyond the expectation and their replies were "overpoliteness" (Leech, 1983, p. 6). This could be attributed to the cultural background of the Iranian participants because Persian language is an honorific language (Koutlaki, 2002). Politeness is a relative concept. For instance, the Japanese and Chinese are considered to be more polite than the Europeans (Leech, 1983). Further, what would constitute being "impolite" in Japan may be considered as "polite" in another country. Locher and Watts (2005, p. 33) argued that "overpoliteness is often perceived as negative exactly because it exceeds the boundary between appropriateness and inappropriateness", and that "the final decision as to whether something is perceived as polite or impolite lies in hearer's interpretation, who judges the 
International Journal of Applied Linguistics \& English Literature

ISSN 2200-3592 (Print), ISSN 2200-3452 (Online)

Vol. 1 No. 7; November 2012 [Special Issue on Applied Linguistics]

relational aspect of the utterance with respect to hearer's own norms (frames, appropriateness, expectations, personal style, etc.)". Whether overpoliteness is taken positively or negatively by interactants needs to be explored empirically.

Partial accommodation responses could be ascribed to pragmatic problems and e-mail literacy. More specifically, the findings here show that the EFL learners did not have sufficient pragmatic knowledge to enable them to write e-mails appropriately when entering a new institutional culture in the target language environment, even though their linguistic ability was at an advanced level. This finding supports Bloch's (2002) perspective that writing a successful e-mail requires more than simple fluency in L2; rather, it requires the ability to express oneself using a variety of linguistic forms and rhetorical strategies, and most importantly, to know when it is appropriate to use them.

\subsection{Research Question 2}

The second research question dealt with the extent to which EFL learners accommodate through converging to verbal markers. Results revealed that the accommodation level of the participants' responses shown by the number of politeness indicators they used was $22 \%$. This indicates that those who had received a message containing politeness verbal markers did not pay attention fully to these markers. That is, those who received messages with verbal politeness indicators alone did not reply in a similarly verbally polite manner.

\subsection{Research Question 3}

The extent of accommodation to structural indicators was found to be $97 \%$. This high percentage of accommodation shows that convergence to these types of e-mail occurred significantly. It also clearly indicates the significance of e-mails containing greeting and closing remarks. The participants modified their linguistic resources (e.g., language choice and vocabulary) to accommodate to the message sent to them; therefore, we could argue that CAT theory is applicable in CMC. Overall, messages with verbal politeness indicators alone did not converge in comparison to those with structural indicators. The participants who received a message with structural indicators were significantly more polite in the greeting section of their responses than were the participants who received a message containing no politeness indicators. That is, the participants accommodated significantly to structural elements in the form of greetings in e-mails.

\subsection{Research question 4}

The extent of accommodation to messages with both structural and verbal politeness indicators was found to be $90 \%$. Although this type of e-mail is assumed to be the most polite message, the received messages did not accommodate fully in comparison to messages with structural markers per se. We realize that verbal politeness indicators are only accommodated significantly when combined with structural elements.

\section{Discussion and Conclusion}

E-mail has been one of the most commonly used forms of building and maintaining social relationship which has been rapidly replacing other means of communication in many institutions of modern life including universities. In university contexts, the nature, goal, and frequency of e-mails may depend on various factors, such as the teaching tradition, technological facilities, and specific course requirements. The purpose of this study was to investigate how EFL learners accommodate to politeness indicators in e-mail interactions. Overall, the results indicated that certain politeness features are accommodated. This provides a new perspective on previous research which argues that the absence of face-to-face interaction in CMC fosters the use of flagrant and hostile language known as "flaming". It is possible to reduce flaming and instead to stimulate politeness by including basic politeness indicators in one's online messages. The participants received one of the four message types (i.e., structural, verbal, structural and verbal, and no politeness markers). Each e-mail version had the same content but varied in politeness level. The participants did not accommodate to verbal politeness markers in the body of their replies. The extent of accommodation to this type of message was found to be only $22 \%$. Not accommodating fully to verbal politeness markers could be attributed to pragmatic problems occurring in the participants' e-mail practice. The pragmatic problems can be of not only the pragmalinguistic type such as a modal use, hedging expressions, and information sequencing, but also of the sociopragmatic type such as status maintenance, politeness realization, and identity construction. Not fully accommodating to verbal politeness markers could be ascribed particularly to pragmaliguistic failure.

This research confirms the findings of previous research on advanced L2 learners' pragmatic ability. That is, "high levels of grammatical competence do not guarantee concomitant high levels of pragmatic competence" (Bardovi-Harlig, 1999, p. 686). Pragmatic competence has been defined to be "the most difficult aspect of 


\section{International Journal of Applied Linguistics \& English Literature}

ISSN 2200-3592 (Print), ISSN 2200-3452 (Online)

Vol. 1 No. 7; November 2012 [Special Issue on Applied Linguistics]

language to master in learning a second language" (Blum-Kulka \& Sheffer 1993, p. 219). Kasper believes that "without some form of instruction, many aspects of pragmatic competence do not develop sufficiently" (Kasper 1997, p. 3). Accordingly, raising EFL learners' pragmatic awareness especially in academic writing courses about appropriate means of interaction with their interlocutors can substantially improve their CMC interactions and their assimilation into their respective institutional cultures. Nonaccommodation (divergence) to messages containing verbal politeness markers represents the importance of developing pragmatic competence for Iranian EFL learners to carry out successful e-mail communication, such as the ability to perform speech acts and use appropriate communication strategies in the online environment. L2 learners' limited experience with the e-mail medium might make their e-mail use ineffective or problematic (Biesenbach-Lucas, 2007). It might be the case that these learners are simply uncertain about e-mail etiquette due to lack of experience and typically because it is not explicitly taught. As such, L2 learners need to learn appropriate ways of both interacting with and using the medium. It is important for L2 learners to learn how to use appropriate discourse forms and strategies to demonstrate those socioculturally appreciated values, as well as to perform their desirable identities. More importantly, they need to be made aware that every discourse practice is socioculturally value-laden and that the appropriateness of every practice is determined by a dominant sociocultural group, not by individual preference (Fairclough, 1995). Such critical language awareness along with pragmatic competence is imperative for L2 learners to develop their e-mail literacy. L2 learners should be taught in the L2 classroom how to communicate appropriately via e-mail, as these appropriateness rules are usually hidden and difficult to acquire.

The participants were found to accommodate significantly (97\%) to structural indicators of greeting or closing, i.e. when such indicators were included in the requests, they responded with significantly more polite messages in the greeting and body sections than when the indicators were absent. The absence or presence and the type of greeting set the tone for the e-mail conversation that follows. Greeting is one means by which the writer constructs his or her social and professional identity and relationship with addressee(s). A closing can help consolidate the relationship and establish a relational basis for future encounters. Thus, simply by including a greeting such as "Dear..." a message is perceived as more polite, and this politeness is mirrored and accommodated by a similar level of politeness in the responding e-mail message. By definition, a message creator's request is separated from the recipient's reply by time and space; co-presence is unnecessary. Therefore, politeness evaluations of the entire conversational turn (sender and receiver) are not strictly necessary. However, we found that politeness was observed in an asynchronic communication context. The results of the present study found the strong support for Walther's (1996) observation that CMC technologies, notably low bandwidth, asynchronous, text-based CMC, can facilitate socially desirable communication. The findings show that messages containing salutation and closing remarks (structural elements) led to more polite messages and the participants were significantly more polite in the form of greetings of their responses. This finding is in line with Kankaanranta (2005) who found that the use of salutations in messages seems to be more common among non-native English speakers, as the use of salutations was also common among the participants in this study. The present study highlights the importance of greetings and closings in e-mail responses; they can offer formulas to ease the strain created for face by the beginning and ends of interactions. By using salutations, the writer "constructs a relationship with the recipient and the usage contributes to the maintenance of social relationship" (Kankaanranta, 2005, p. 359).

No significant interaction effect was found between verbal markers and structural elements. This means that including both kinds of politeness cues in an e-mail message does not necessarily stimulate significantly more polite response than including either verbal or structural elements. Compared with the study by Buzzanell et al. (1996), we see identical accommodations to similar message types in two different media of communication, that is, telephone messages and e-mail messages. Buzzanell et al. (1996) found that student-callers accommodated significantly to the telephone messages containing structural markers and verbal politeness markers to enhance perceptions of similarity to their interaction partners. They found that callers seemed to follow the callee's lead for terms of address, greeting, and closings as the participants of this study did. All in all, these results show that even in mediated communication exchanges where there are very few opportunities to converge, individuals still modify their language choices and some message features to display similarity with interaction partners which suggest that people converge to messages even in very limiting communication contexts.

Pedagogically speaking, linguistic politeness has a central place in foreign language teaching, and foreign language teaching must be adjusted to incorporate a pragmatic perspective. It is believed that politeness theory offers adequate tools to teach linguistic forms in context. Further, teaching students institutional e-mail practice can be a good starting point for the development of e-mail literacy since without instruction learners' language production tends to diverge from native speaker norms and may result in negative assessments of their 
International Journal of Applied Linguistics \& English Literature

ISSN 2200-3592 (Print), ISSN 2200-3452 (Online)

Vol. 1 No. 7; November 2012 [Special Issue on Applied Linguistics]

personalities and even their cultural group. While the current study examined accommodation politeness theory in e-mail messages without any prior direct instruction, research has shown that pedagogical intervention with regard to instruction and acquisition of appropriate speech act performance (e.g., discovery and raising of metapragmatic awareness) is helpful for non-native speakers (NNSs) of English (Bardovi-Harlig 2001; House, 2003; Kasper, 2001).

Overall, this research adds to the literature on social cues on CMC, social information processing, and accommodation theory in the mediated context by showing that politeness can be expressed easily in e-mail, where it then acts as a social cue to enrich mediated electronic communication. E-mail recipients are capable of detecting politeness indicators, and consciously or not, accommodate to this politeness by including similar politeness indicators in their e-mail responses. Convergence takes place when an e-mail response mirrors the politeness cues of the original message. Also, this research reinforces CMC literature (Walther ,1992; Walther, Anderson \& Park, 1994) in the sense that effective interpersonal communication can occur in CMC. Certain social cues may be filtered out by communication technologies, but politeness indicators were communicated, interpreted, and reciprocated, allowing the participants to build towards positive impression in their e-mail responses. This study was an attempt to describe and analyze politeness accommodation in e-mail messages. Nonetheless, several potentially intriguing factors remain unexamined. Future studies might look at a broader spectrum of students, including graduate students from a variety of academic fields of study and undergraduate students whose computer experience most likely began at much earlier age than that of postgraduate students. Finally, research should focus on pedagogical intervention and investigate what type of instructional (explicit, implicit and awareness-raising) is effective in helping language learners compose polite and effective e-mail messages. Factors such as proficiency level, amount of input and practice, length of exposure to the target culture and academic environment, and pragmatic transfer could be controlled to determine optimal intervention. As e-mail becomes as commonplace as the telephone, ESL teaching materials will thus need to include e-mail communication as a regular course component. It should be noted though that teaching of politeness strategies needs to go beyond presenting politeness markers as conventionalized formulae for NNSs to communicate effectively in social situations.

\section{References}

Bardovi-Harlig, K. (1999). Exploring the interlanguage of pragmatics: A research agenda for acquisitional pragmatics. Language Learning, 49 (4), 677-713.

Bardovi-Harlig, K. (2001). Evaluating the empirical evidence: Grounds for instruction in pragmatics? In K. R. Rose \& G. Kasper (Eds.) Pragmatic language teaching (pp. 13-32). Cambridge: Cambridge University Press.

Biesenbach-Lucas, S. (2007). Students writing e-mails to faculty: An examination of e-politeness among native and non-native speakers of English. Language Learning \& Technology, 11(2), 59-81.

Bloch, J. (2002). Student/teacher interaction via e-mail: The social context of the Internet discourse. Journal of Second Language Writing, 11, (2) 117-134.

Blum-Kulka, S., and Sheffer, H. (1993).The metapragmatic discourse of American-Israel families at dinner. In Interlanguage Pragmatics, Gabriel Kasper and Soshana Blum-Kulka (Eds.), 196-223. Oxford: Oxford University Press.

Brown, P., \& Levinson, S. (1987). Politeness: Some universals in language usage. Cambridge, MA: Cambridge University Press.

Bunz, U., \& Campbell, S. (2002). Accommodating politeness indicators in personal electronic mail messages. Paper presented at the Association of Internet Research's $3^{\text {rd }}$ Annual Conference Maastricht, The Netherlands. Retrieved December 24, 2009 from http://bunz.comm.fsu.edu/AoIR2002 politeness.pdf

Buzzanell, P., Burrell, N., Stafford, S., \& Berkowitz, S. (1996). When I call you up and you're not there:

Application of communication accommodation theory to telephone answering machine messages. Western Journal of Communication, 60, (3) 310-336.

Culnan, M., \& Markus, M. (1987). Information technologies. In F. Jablin, L. Putnam, K. Roberts \& L. Porter (Eds.), Handbook of Organizational communication: An interdisciplinary perspective (pp. 120-128). Thousand oaks, CA, US: Sage Publications, Inco.

Duthler, K. W. (2006). The politeness of requests made via e-mail and voicemail: Support for the hyperpersonal model. Journal of Computer-Mediated Communication, 11 (2), article 6. Retrieved December 24, 2009, from 
International Journal of Applied Linguistics \& English Literature

ISSN 2200-3592 (Print), ISSN 2200-3452 (Online)

Vol. 1 No. 7; November 2012 [Special Issue on Applied Linguistics]

http://jcmc.indiana.edu/vol11/issue2/duthler.html

Fairclough, N. (1995). Critical discourse analysis: The critical study of language. New York: Longman.

Giles, H., Mulac, A., Bardac. J., \& Johnson, P. (1987). Speech accommodation theory: The first decade and beyond. In M. L. McLaughlin (Ed.), Communication Year book, (pp.10-11). Beverly Hills, CA: Sage Publications, Inco.

Goffman, E. (1955). On face-work: An analysis of ritual elements in social interaction. Psychiatry: Journal of the Study of Interpersonal Process (2) (3), 213-231.

Haugh, M. (2004). Revisiting the conceptualization of politeness in English and Japanese. Multilingua, 23 (1/2), 85-109.

Holtgraves, T., \& Yang, J. (1992). Politeness as universal: Cross-cultural perceptions of request strategies and inferences based on their use. Journal of Personality and Social Psychology, 59(4), 719-729.

House, J. (2003). English as a lingua franca: A threat to multilingualism. Journal of Sociolinguistics, 7(4), 556-578.

House, J. (2005). “Politeness in Germany: Politeness in Germany?” In L. Hickey \& M. Stewart (Eds.), Politeness in Europe. Clevedon: Multilingual Matters Ltd: 13-28.

Kankaanranta, A. (2005). "Hej Seppo, Could You Pls Comment on This!" Internal E-mail Communication in Lingua Franca English in a Multinational Company.Ph.D. dissertation, Centre for Applied Language Studies, University of Jyväskylä. Retrieved January 18, 2009 from http://ebooks.jyu.fi/solki/9513923207. pdf Kasper, G. (1992). Pragmatic Transfer. Second Language Research, 8 (3), 203-231.

Kasper, G. (1997). Linguistic politeness: Current research issues. Journal of Pragmatics, 14, 193-218.

Kasper, G. (2001). Classroom research on interlanguage pragmatics. In K. R. Rose \& G. Kasper (Eds.), Pragmatics in language teaching. Cambridge: Cambridge University Press.

Kiesler, S., Siegel, J., \& McGuire, T. (1984). Social psychological aspects of computer- mediated communication. American Psychological, 39, 1123-1134.

Koutlaki, S. (2002). 'Offers and expressions of thanks as face enhancing acts: Tæ'rof in Persian'. Journal of Pragmatics, 34 (12), 1733-1756.

Leech, G. (1983). Principles of Pragmatics. London: Longman.

Locher, M., \& Watts, R. J. (2005). Politeness theory and relational work. Journal of Politeness Research, 1 (1), 9-34.

Noblia, M.V. (1998). The computer-mediated communication: a new way of understanding the language", IRISS'98, Internet Research and Information for Social Scientists. (pp.10-12) 25-27 March 1998, Bristol, UK. Retrieved January 18, 2008 from http://www.intute.ac.uk/socialsciences/archive/iriss/papers/paper22.htm O’Sullivan, P., \& Flanagin, A. (2003). Reconceptualizing 'flaming' and other problematic messages. New Media \& Society, 5 (1), 69-94.

Pickering, J., \& King, J. (1995). Handwriting Weak Ties: Interorgazational Computer-Mediated Communication, Occupational Communities, and Organizational Change. Organizational Science, 6, 479-489.

Sproull, L., \& Kiesler, S. (1986). Reducing social context cues: Electronic mail in organizational communication. Management Science, 32, 1492-1512.

Tracy, K. (1990). The many faces of facework. In H. Giles \& W. P. Robinson (Eds.), Handbook of Language and Social Psychology. Chichester: John Wiley.

Walther, J. (1992). Interpersonal effects in computer-mediated interaction: A relational perspective.

Communication Research, 19, 52-90.

Walther, J. B. (1996). Computer-mediated communication: Impersonal, interpersonal, and hyper-personal interaction. Communication Research, 23 (1), 3-43.

Walther, J., Anderson, J., \& Park, D. (1994). Interpersonal effects in computer-mediated interaction: A meta-analysis of social and antisocial communication. Communication Research, 21, 460-487.

Walther, J. B., \& Parks, M. (2002). Cues-filtered-out-cues filtered in: CMC and relationship. In M. Knapp \& J. Daly (Eds.), Handbook of Interpersonal Communication (pp. 529-563). Thousand Oaks, CA: Sage Publications, Inco.

Yang, W. X. (2007).On pragmatic information in learners'dictionaries, with particular reference to $\mathrm{LDOCE}_{4}$. International Journal of Lexicography, 20 (2), 147-173. 